\title{
Analysis of microstructure and difference of 6 species of remiges in Galliformes
}

Jing Jiang

Department of Criminal Science and Technology, Nanjing Forest Police College, Nanjing 210023

\begin{abstract}
To study the microstructure and difference of remiges in galliformes, the Silver Pheasant (Lophura nycthemera), golden pheasant (Chrysolophus pictus), Blue Eared Pheasant (Crossptilon auritum), Koklass Pheasant (Pucrasia macrolopha), Himalayan Snowcock (Tetraogallus himalayensis) and Thunderbird (Tetrao urogallus) were selected as the representative of six species of endangered birds. The scanning electron microscopy (SEM) was adopted to photograph and count the hooked barbule, cilia and ventral tooth, meanwhile, the single factor analysis of variance of different remiges was carried out by Spss 11.5 software. The results show that remiges are mainly composed of hook feathers and proximal barbule, and there are hook feathers on the side of a small hook, but also with cilia. Proximal barbule is mainly composed of ventral tooth, whose number and shape are the main features. The number of hooked barbule, cilia and ventral tooth of proximal barbule of the remiges of the different birds were significantly different or significant differences among the two species, which could provide the basis for identification.
\end{abstract}

\section{Introduction}

Law enforcement agencies such as the forest public security administration often seized a large number of birds that have been stripped, salted, etc., which are difficult to use traditional morphological methods for species identification. Bird feathers often become evidences that are easily found on the spot. The use of bird's feather microstructural characteristics for species inspection and identification, to determine whether it is a national key protection category, for the illegal hunting, transportation, trafficking of wild birds' cases have important application value.

The observation of feather microstructure mainly focuses on contour feathers, down feathers and hairiness, and the research on flying feathers in contour feathers is more prominent ${ }^{[1-3]}$. Foreign studies on the microscopic structure of bird feathers using electron microscopy began in the late 1970s, focusing on the observation and data accumulation of different bird feathers $[4,5]$; The researches were relatively lagging, not comprehensive, and mainly aimed at regional distribution of birds [6-8]. Due to the different concerns or points of interest of the research, there are few studies to focus on the key protective bird feathers.
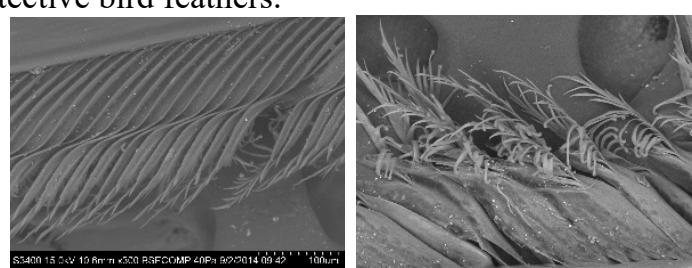

(a) Lophura nycthemera
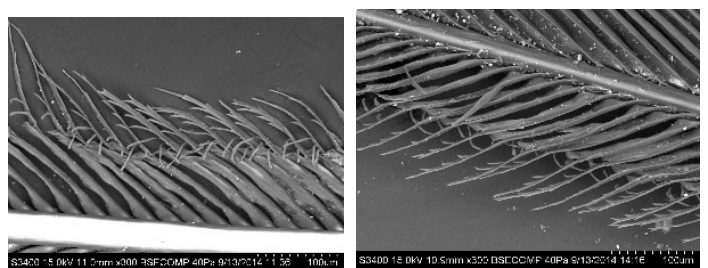

(b)Chrysolophus pictus
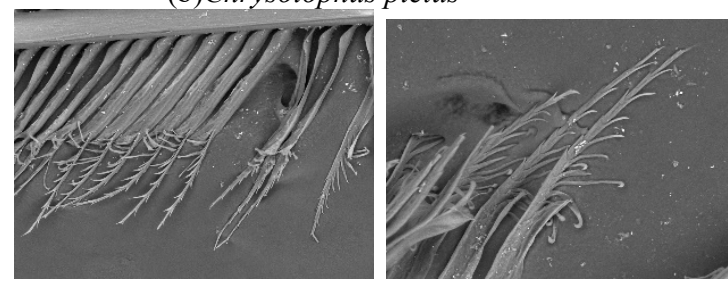

(c) Crossptilon auritum
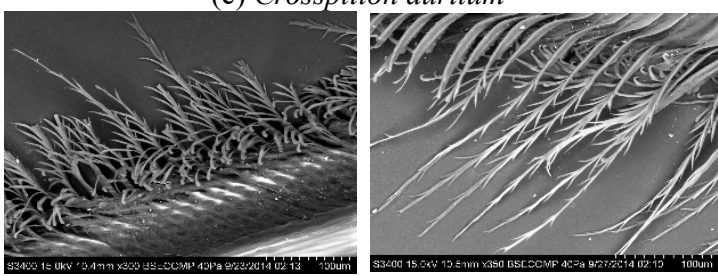

(d) Pucrasia macrolopha

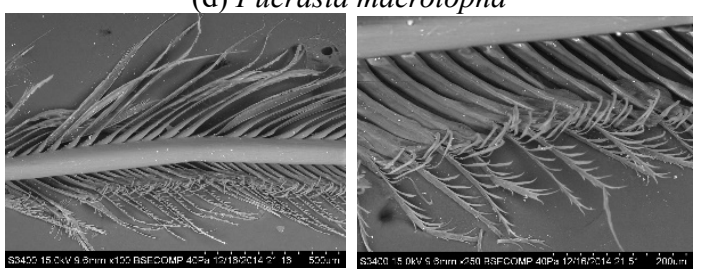

(e) Tetraogallus himalayensis 


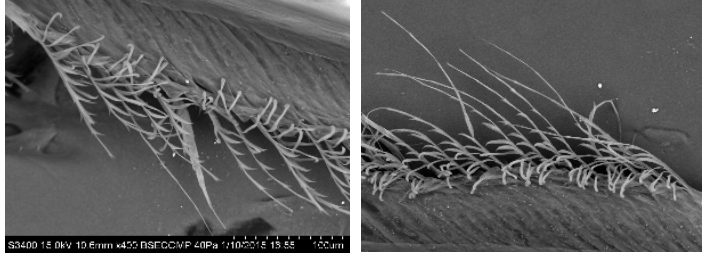

(f) Tetrao urogallus

Figure 1. Micro-structure of 6 species of remiges in barbules

Most of the species of the genus Diptera are national key protective animals. In this paper, six species of endangered birds in the genus Diptera are studied, namely Lophura nycthemera, Chrysolophus pictus, and Crossptilon. Auritum, Pucursia macrolopha, Tetraogallus himalayensis and Tetrao urogallus. The microstructure characteristics of endangered bird feathers were analyzed by scanning electron microscopy. After summed up all the data and carried out One-way analysis of variance, a method for identifying different birds using bird feather microstructural examination was proposed. Based on the research of scholars at home and abroad, this study focuses on precious and endangered wild birds, and uses feather microstructure to identify birds, which can provide effective evidence for law enforcement cases.

\section{Sample preparation}

The bird samples selected in this paper were collected from the Bird Specimen Museum of Nanjing Forest Police College and sent samples. A total of 6 species of bird feathers were collected. (Lophura nycthemera, Chrysolophus pictus, Crossptilon auritum, Pucurasia macrolopha, Tetraogallus himalayensis and Tetrao urogallus), each of which selects 5 samples with wing and tail feathers, and puts the feather sample into $95 \%$ ethanol mixture with diethyl ether (volume ratio of $1: 1$ ) was degreased for $20 \mathrm{~min}$, then washed with absolute ethanol for $2 \mathrm{~min}$, taken out with filter paper or dried naturally for use [9].

\section{Flying feather microstructure analysis}

\subsection{Flying feather microstructure}

Differential analysis of feather microstructure contributes to the identification of bird species. In this paper, Hitachi S-3400II scanning electron microscope was used to observe the microstructure of the processed bird feather samples, and the magnification was 100-5000 times. The photos of the feather hooks, cilia and abdomen were taken and counted. The electron microscope parameters are set to: accelerating voltage $(10-15 \mathrm{KV})$, low vacuum $(30-40 \mathrm{~Pa})$ and backscattering (BSE). Because the microscopic features and measurement data of different parts of the same feather have great differences, the experimental comparison shows that the characteristics of the middle or middle part of the plume are relatively stable, so the experiment is selected here for observation. The typical microstructure of six different bird feathers is shown in Figure 1.
For the six species of chicken-shaped endangered birds selected in this paper, the typical microscopic morphology of the six kinds of flying feathers in the figure can be obtained. The main features are: contour feathers mainly consisting of hook feathers and no hook feathers. The branchlets are composed of a branch with a feathered branch. In addition to the small hooks, there are also cilia. The side of the branch without hooks is mainly the abdomen, and its number and shape are the main feature points. The feathers are mainly composed of nodes. The composition of the plume, the knot width, the length of the knot, the diameter of the knot and the shape of the plume are the main feature points. Most of the feather plumes on the flying feathers form a feather piece, and the feather branches are obliquely born on the feather shaft, and the angle is less than or close to $45^{\circ}$, which is arranged in a slightly inclined shingle shape; the side of the feather branch is a branch with hook feathers. On the other side is a branch without hook feathers. The plumes are slanted on the plume, and the angle is generally less than $45^{\circ}$. The different feathers of different parts are densely spaced from each other, and the plumes on both sides of the plume Many are not right; the hooked feather branches and the non-hooked branchlets of adjacent feather branches can be tightly hooked together to form a solid feather piece, and some of them are not tightly connected and loose.

For the six species of chicken-shaped birds selected in this paper, it can be seen from the analysis that the feather plume has the following characteristics: for white pelicans, its feather plume is closely arranged, the gap is small, and the middle or lower part (without the abdomen) Or the plume of the feathered hook. The plume is wider, and there are more than 6-7 feather hooks on the side of the hook plume. The cilia are less, and 3-5 pairs appear in pairs. More bifurcation, the length of the cilia appearing in pairs is close to or the side is significantly longer than the other side, the plume is flat; the number of abdomen teeth is $3-5$, the position of the birth is concentrated, and the tip is slender. For the golden-bellied golden pheasant, the branchlets of the feather plume are looser, the middle or lower part of the plume is wider, the feather hook is more than 2-4, and it is more obvious. The number of cilia is less, and many are not in pairs. Or one side is not obvious, 3-5 (pair), the top part is forked or not bifurcated, the plume is flat; the number of abdomen teeth is 3-5, slender and obvious. For the blue-horse chicken, its flying feathers are not closely arranged, and the feather hooks are 4-5 more, which is more obvious. The number of cilia is less, some are in pairs, about 6-8 (pair), plume two The length of the side cilia is obviously different, the top is more bifurcated, the plume is flat; the abdomen teeth are $3-5$, the arrangement is more tightly concentrated, and the teeth are longer. For the scoop chicken, the branchlets of the feather plume are not very tightly arranged, the feather hooks are 5-7 more and obvious, the number of cilia is more, the pair appears, and the lengths of the two sides are close, more than 6-9 pairs, the top part The fork is not obvious; the abdominal teeth are 3-5, the arrangement is more closely concentrated and obvious, and the tip of the feather branch is thinner. For the dark-bellied snow chicken, its flying feather plumes are not closely arranged, the feather hooks are 4-6 pieces and obvious, the number 
of cilia is more, paired or unpaired, 8-11 pairs (one), one side cilia Longer, the top part of the fork is not obvious, the plume is flat; the belly teeth are 4-6, the position of the abdomen is concentrated, the proximal part begins to disperse, and the tip of the feather branch is thin. For Thunderbirds, the branches of the feathers are closely arranged, the feather hooks are 4- 6 pieces and obvious, the number of cilia is small, the pairs appear in pairs, the length varies, 7-10 pairs, the top part is not obvious or not; The plume is wide and the abdominal teeth are $3-4$, the position of the abdomen is concentrated, and the tip of the plume is slender.

Through the observation of the microscopic structure of the flying feathers of six species of chickens, it is found that the above characteristics of the species are relatively stable, and there are certain differences among the species. According to the intra-species stability and interspecies variability of the feather microstructure, the species can be the basis for identification is provided.

Table1 Comparison on the difference of barbules structures of 6 species of remiges in galliformes

\begin{tabular}{|c|c|c|c|c|}
\hline \multirow{2}{*}{ Item } & \multirow{2}{*}{ Species } & \multicolumn{2}{|c|}{ Distal barbule } & Proximal barbule \\
\hline & & Number of hooked barbule & Number of cilia & Number of ventral tooth \\
\hline 1 & Lophura nycthemera & $6.6 \pm 0.6$ & $4.4 \pm 0.7$ & $4.2 \pm 0.5$ \\
\hline 2 & Chrysolophus pictus & $2.8 \pm 0.5$ & $3.7 \pm 0.6$ & $3.9 \pm 0.7$ \\
\hline 3 & Pucrasia macrolopha & $6.2 \pm 0.5$ & $7.8 \pm 1.3$ & $3.8 \pm 0.7$ \\
\hline 4 & Crossptilon auritum & $4.5 \pm 0.7$ & $6.9 \pm 0.9$ & $4.1 \pm 0.6$ \\
\hline 5 & Tetraogallus himalayensis & $5.0 \pm 0.7$ & $9.7 \pm 1.2$ & $5.0 \pm 0.6$ \\
\hline 6 & Tetrao urogallus & $5.0 \pm 0.6$ & $8.4 \pm 2.0$ & $3.6 \pm 0.5$ \\
\hline
\end{tabular}

Note: Values in the table are mean \pm SE.

\subsection{Analysis of the difference in the structure of the plume}

By analyzing and comparing the microscopic features of different types of bird feathers observed, the feature points that can be used for identification are determined. Using Spss11.5 software, statistical analysis was carried out on the number of feather hooks on the side of the hook feathers, the number of cilia and the number of abdomen teeth on the side of the hookless branch of the different bird species in the above six species. The significance analysis was performed by one-way analysis of variance. $\mathrm{P}<0.05$ indicated that the difference was significant, and $\mathrm{P}<0.01$ indicated that the difference was extremely significant, to obtain the difference between the above indicators in different birds.

Table 1 shows the results of the number of small hooks on the side of the hooked plume of the six species of the squid, the number of cilia, the number of abdomen and the number of abdomen on the side of the hookless branch. It can be seen from the table that there are many differences in the indicators of the flying feathers of the six species of chickens, so the identification process.

Table2 Analysis of the difference of hooked barbule from 6 species of remiges in galliformes

\begin{tabular}{|c|c|c|c|c|c|}
\hline Species & $\begin{array}{c}\text { Lophura } \\
\text { nycthemera }\end{array}$ & $\begin{array}{l}\text { Chrysolophus } \\
\text { pictus }\end{array}$ & $\begin{array}{c}\text { Pucrasia } \\
\text { macrolopha }\end{array}$ & $\begin{array}{c}\text { Crossptilon } \\
\text { auritum }\end{array}$ & $\begin{array}{l}\text { Tetraogallus } \\
\text { himalayensis }\end{array}$ \\
\hline Chrysolophus pictus & $1064.03 * *$ & & & & \\
\hline Pucrasia macrolopha & $9.824 * *$ & $1165.833 * *$ & & & \\
\hline Crossptilon auritum & $245.385 * *$ & $229.973 * *$ & $208.242 * *$ & & \\
\hline $\begin{array}{l}\text { Tetraogallus } \\
\text { himalayensis }\end{array}$ & $141.772 * *$ & $318.977 * *$ & $104.875^{* *}$ & $9.474 * *$ & \\
\hline Tetrao urogallus & $155.865^{* *}$ & $358.258 * *$ & $118.018^{* *}$ & $10.713 * *$ & 0 \\
\hline
\end{tabular}

Table3 Analysis of the difference of cilia from 6 species of remiges in galliformes

\begin{tabular}{|c|c|c|c|c|c|}
\hline Species & $\begin{array}{c}\text { Lophura } \\
\text { nycthemera }\end{array}$ & $\begin{array}{l}\text { Chrysolophus } \\
\text { pictus }\end{array}$ & $\begin{array}{l}\text { Pucrasia } \\
\text { macrolopha }\end{array}$ & $\begin{array}{l}\text { Crossptilon } \\
\text { auritum }\end{array}$ & $\begin{array}{l}\text { Tetraogallus } \\
\text { himalayensis }\end{array}$ \\
\hline Chrysolophus pictus & $32.667 * *$ & & & & \\
\hline Pucrasia macrolopha & $257.283 * *$ & $410.64 * *$ & & & \\
\hline Crossptilon auritum & $245 * *$ & $475.882 * *$ & $16.473 * *$ & & \\
\hline $\begin{array}{l}\text { Tetraogallus } \\
\text { himalayensis }\end{array}$ & $728.259 * *$ & $1039.927^{* *}$ & $54.847 * *$ & $176.22 * *$ & \\
\hline Tetrao urogallus & $326.922 * *$ & $495.027 * *$ & 3.949 & $39.558^{* *}$ & $26.821 * *$ \\
\hline
\end{tabular}


Table4 Analysis of the difference of ventral tooth of proximal barbule from 6 species of remiges in galliformes

\begin{tabular}{cccccc}
\hline Species & $\begin{array}{c}\text { Lophura } \\
\text { nycthemera }\end{array}$ & $\begin{array}{c}\text { Chrysolophus } \\
\text { pictus }\end{array}$ & $\begin{array}{c}\text { Pucrasia } \\
\text { macrolopha }\end{array}$ & $\begin{array}{c}\text { Crossptilon } \\
\text { auritum }\end{array}$ & $\begin{array}{c}\text { Tetraogallus } \\
\text { himalayensis }\end{array}$ \\
\hline Chrysolophus pictus & $7.951^{* *}$ & & & & \\
Pucrasia macrolopha & $12.527^{* *}$ & 0.327 & & & \\
Crossptilon auritum & 1.336 & 2.981 & $5.704^{*}$ & & \\
Tetraogallus himalayensis & $49.521^{* *}$ & $70.683^{* *}$ & $83.286^{* *}$ & $57.925^{* *}$ & $152.976^{* *}$ \\
Tetrao urogallus & $38.958^{* *}$ & $4.598^{*}$ & 2.274 & $21.063^{* *}$ & 150 \\
\hline
\end{tabular}

\section{Difference analysis of various structures of flying feathers}

Comparing and analyzing the number of feather hooks on the side of the hook feathers, the number of cilia, and the number of abdomen teeth on the side of the hookless branch, in the above-mentioned chickens, as shown in Table 2-4, One-way ANOVA was performed using Spss11.5 software to obtain the difference between the above indicators in different birds.

It can be seen from Table 2-4 that there are significant or extremely significant differences between the two species in the number of small feathers, the number of cilia, and the number of abdomen teeth on the side of the hookless plume in different birds. The difference between the few species is not significant, which indicates that it is feasible to identify different birds in the scorpion by these parameters.

\section{Conclusion}

In this paper, photographic electron microscopy was used to photograph and count the feather hooks, cilia and abdomen on the feathers of six species of chicken-shaped endangered birds. At the same time, different birds were feathered in the above-mentioned chickens using Spss11.5 software. A one-way analysis of variance was performed to obtain the degree of difference between the above indicators in different birds. Through the research of this paper, the following conclusions are obtained:

(1) The flying feathers of the scorpion-shaped birds are mainly composed of hooked twigs and non-hooked twigs. The side of the hooked twigs is sessile with the snails on the side of the stalks. Mainly the abdomen, its quantity and shape are the main feature points;

(2) Most of the feather plumes on the flying feathers form a feather piece, which is obliquely born on the feather shaft, and its angle is less than or close to $45^{\circ}$, which is arranged in a slightly inclined shingle shape; the different feathers of different parts are placed between each other. The spacing between the students is uneven, and the plumes on the two sides of the plume are not opposite; the hooks and hooks of the adjacent branches can be tightly hooked together to form a solid vane, and some of them hooked loosely.

(3) There are significant or extremely significant differences in the number of small feathers, the number of cilia, and the number of abdomen teeth on the side of the hooks in the six species of chickens. There are only a few differences between the two species. Not significant, so the above measurement data can be used in the identification process as a basis for identification of different birds in the shape of the chicken.

\section{Fund Project:}

Funded by the State Forestry Administration Key Research Project (2013-03).

\section{References:}

1. Li Honghui, Shen Yuhui, Ma Zaiyu. Comparison of Microstructure of Bird Flying Feather Twigs[J]. Acta Classification Sinica, 2005(4): 666-675.

2. Fan Xishun. Scanning electron microscopic observation of 25 species of bird feathers in the order of the bird[J]. Journal of Shihezi University (Natural Science), 1997(3): 4

3. Chang Chongyan, Zhang Zhengwang, Chen Xiaoduan. Discussion on the Ultrastructure of Brown Pheasant Feather[J]. Journal of Chinese Electron Microscopy, 2001(4): 495-496.

4. Li Honghui, Shen Yuhui, Lai Qin. Microstructure of 20 species of bird feathers and feathers[J]. Journal of Natural Science of Hunan Normal University, 2005(3): 68-71.

5. Hu Shijia, Wang Lili, Peng Jianjun. Research and Prospect of Microscopic Identification Technology and Application of Bird Feather[J]. Sichuan Animals, 2008(4): 699-702.

6. Xia Xiaofei, Wang Ying, Wu Xiushan, et al. Scanning electron microscopic observation of Zhu Xi's feathers $[\mathrm{J}]$. Journal of Northeast Forestry University, 2010(12): 130-131.

7. Song Chunfeng, Li Xiangyin, Ying Guohua. Scanning electron microscopic observation of bird feathers[J]. Bulletin of Biology, 1991(3): 9.

8. Hou Lin, Xue Xiaoming, Song Qingshuang. Scanning Electron Microscopy Analysis of Purple Needle Hairs[J]. Journal of Anhui Agricultural University, 2012, 39(1): 22-25.

9. Hou Forest. Comparison of Microstructures of 10 Species of Flying Feathers of Scorpionfish[J]. Journal of Anhui Agricultural University, 2014, 39(1): 358362. 